Revista Destaques Acadêmicos, Lajeado, v. 8, n. 4, 2016. ISSN 2176-3070 DOI: http://dx.doi.org/10.22410/issn.2176-3070.v8i4a2016.1201 www.univates.br/revistas

\title{
PRODUÇÃO DE DOCE BRIGADEIRO COM LEITE DE ARROZ CONTENDO TRAÇOS DE LACTOSE
}

\author{
Jênifer Jennrich ${ }^{1}$, Priscila de Oliveira Gauer ${ }^{1}$, Rosemeri Scherer ${ }^{1}$, \\ Felipe Diego Davies², Tamares Scherer', Michele Ramos Dutra Rosolen ${ }^{3}$
}

\begin{abstract}
Resumo: Entende-se por brigadeiro o produto cozido feito de leite, manteiga, açúcar e chocolate, preparado à base de leite condensado e chocolate, podendo ser acrescido de outros ingredientes, sendo um doce típico da culinária brasileira, famoso e conhecido em todo país. O objetivo do presente trabalho foi desenvolver e avaliar as características físico-químicas e sensoriais de uma massa de brigadeiro com teor reduzido de lactose. Dessa forma, foram elaboradas três diferentes formulações, onde foram variadas as matérias primas base que foram: o leite de arroz e o leite condensado sem lactose. Nas análises físico-químicas não foi possível comparar os resultados, pois não existe legislação para o produto desenvolvido, porém a resolução - CNNPA n ${ }^{\circ}$ 12, de 1978 da ANVISA, dispõe de alguns critérios para a padronização de doce de leite que serão tomados como base, como umidade máxima de 30\%, lipídios com o mínimo de 2,0\% e proteínas com o mínimo de 6,0\% e cinzas de no máximo 2,0\%. Quanto aos resultados de análise sensorial pode-se observar que não houveram variações significativas entre as amostras em nenhum dos atributos de aparência, odor, textura, impressão global e sabor. Comprovou-se que o leite de arroz pode substituir parcialmente o leite condensado deixando o produto com características sensoriais de brigadeiro, mas com menos gordura e mais proteína se comparado ao brigadeiro tradicional, e devese considerar os nutrientes disponíveis no leite de arroz, podendo ser uma alternativa viável, principalmente na alimentação infantil.
\end{abstract}

Palavras-chave: Brigadeiro. Lactose. Leite de arroz.

1 Graduando curso de Engenharia de Alimentos do Centro Universitário UNIVATES.

2 Graduando curso de Química Industrial do Centro Universitário UNIVATES.

3 Professora com Graduação em Nutrição da Universidade Federal de Pelotas (2004). Especialista em Nutrição Clínica pela UGF (2006). Mestre em Biotecnologia pelo Centro Universitário UNIVATES (2015). 


\section{INTRODUÇÃO}

A preocupação dos consumidores em relação à alimentação vem se intensificando cada vez mais. Isso se deve a uma grande parte da população adquirir, com o passar dos anos ou simplesmente já nascer com algum tipo de alergia e/ou intolerância. O que também pode ser destacado é que o alimento, anteriormente considerado apenas fonte de energia e nutrientes essenciais à manutenção da vida, tornou-se alvo de muitos estudos que o relacionam a prevenção de doenças e melhoria das funções de órgãos e tecidos (SALGADO et al., 2001).

A má absorção ou má digestão de lactose é a diminuição na capacidade de hidrolisar, ou seja, quebrar a molécula de lactose resultando em glicose e galactose, que é resultante da hipolactasia. A hipolactasia significa diminuição da atividade da enzima lactase na mucosa do intestino delgado, gerando o surgimento de sintomas abdominais com intensidade variada, como: dor abdominal, diarreia, náuseas e flatulências decorrentes da má digestão da lactose e que caracterizam a intolerância à lactose (CUNHA et al., 2008; MATTAR; MAZO, 2010; PEREIRA et al., 2012).

Os estudos epidemiológicos mostram que populações nos seus primórdios dependiam da pecuária muito mais que da agricultura, eram grandes consumidores de leite e laticínios em geral, apresentaram menor prevalência de intolerância à lactose em relação àquelas que dependeram mais da agricultura para sobreviver. No entanto, é importante salientar que a produção da enzima não é induzida pelo consumo de lactose (LONGO, 2006; FOOD INGREDIENTS, 2010; GASPARIN; TELES; ARAÚJO, 2010; FAEDO et al., 2013).

No Brasil, em média, mais de $70 \%$ da população adulta apresenta hipolapsia. A incidência é maior ou menor de acordo com a região de origem do indivíduo e fatores genéticos (MATTAR; MAZO, 2010). Como panorama geral, cerca de dois terços da população mundial adulta não apresentam prevalência de lactase (INGREDIENTES, 2010; PEREIRA et al., 2012).

Atrelado a essas questões é que surge a necessidade de produtos com quesito inovador e funcional, direcionando- se dessa forma, para que as indústrias passem a fazer uso de ingredientes alternativos, ou seja, com características diferentes dos que são apresentados ao consumidor atualmente. A indústria de alimentos está buscando auxiliar as pessoas que necessitam de dietas especiais. Uma pesquisa nacional, porém, com referências internacionais, realizada pelo IBOPE e pela FIESP (2010), a Food Trends 2020, evidenciou quais são as principais tendências de consumo de alimentos no Brasil: sensorialidade e prazer, saudabilidade e bem-estar, conveniência e praticidade, qualidade e confiabilidade, sustentabilidade e ética. Com base nos resultados desta pesquisa, as indústrias de ingredientes e produtos acabados está se mobilizando 
para atender às preferências e necessidades dos consumidores (FIESP, 2010; INGREDIENTES, 2010).

Um ingrediente alternativo é a farinha e ou leite de arroz, um elemento promissor na elaboração de produtos. $\mathrm{O}$ que pode ser destacado é que no Brasil esse ingrediente não possui uma linha de produtos bem definida, surge à oportunidade de desenvolver um produto diferenciado. Além da ausência de glúten, a farinha de arroz possui outra vantagem, que é o baixo índice glicêmico, carboidratos são absorvidos lentamente, isso atenua os picos glicêmicos após as refeições e promove maior saciedade. Apesar de todos os benefícios socioeconômicos e nutricionais, a utilização da farinha de arroz ainda é modesta (HEISLER et al. 2008).

Existem no mercado produtos alternativos, com reduzidos teores de lactose, capazes de suprir as necessidades nutricionais desses pacientes, minimizando os riscos de comprometimento da saúde. Entre esses produtos podemos destacar os iogurtes, queijos duros e leites processados com baixos teores deste açúcar (MATTAR; MAZO 2010; SANTIN, 2010; PEREIRA et al., 2012).

O grande número de pessoas que possuem restrições alimentares tem na internet uma forte aliada. Uma simples busca na rede nos leva a sites como

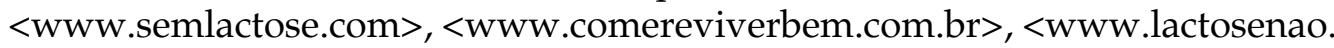
com $>,<w W w . s e m g l u t e n s e m l a c t o s e . c o m>$, onde cada novidade lançada no mercado é informada ao público alvo junto com elogios ou críticas. Portanto, esse é um nicho de mercado em expansão, favorável para investimento das indústrias de alimentos (PEREIRA et al., 2012).

O brigadeiro é considerado uma atrativa guloseima brasileira, que surgiu para homenagear o Brigadeiro Eduardo Gomes que foi candidato à eleição presidencial no fim da Era Vargas, em 1945, caracterizado por meio de mistura de chocolate ao leite condensado (SHINOHARA et al., 2013). É um produto obtido a partir de cozimento, à base de leite condensado e chocolate, podendo ser adicionado de outras substâncias como: manteiga, nozes, castanha-do-Pará, castanha-de-caju e uva passa, envolvido em chocolate granulado ou confeitos coloridos (CNNPA, 1978).

Dentre os ingredientes, o leite condensado é definido como: "leite evaporado" ou "leite condensado sem açúcar", considerado um produto resultante da desidratação parcial, em vácuo, de leite próprio para o consumo, seguido de homogeneização, enlatamento e esterilização. Ele apresenta uma elevada concentração de carboidratos, este fato, impede o desenvolvimento bacteriano, tendo assim, tempo maior de vida de prateleira (ARAÚJO et al., 2012).

O arroz (Oryza sativa) é um alimento nutritivo, baseado em amido (a maior parte); proteínas; sais minerais (fósforo, ferro e cálcio); vitaminas do complexo B; contém oito aminoácidos essenciais presentes no endosperma e 
no farelo do grão que favorecem a digestibilidade; e baixo teor de lipídeos. O extrato de arroz representa uma das alternativas para substituir o leite de vaca pelas suas propriedades nutricionais e baixo custo (JUNIOR et al., 2010).

O chocolate é obtido pelas sementes do cacau, e representa uma fonte alimentar de gordura e polifenóis, excelentes antioxidantes. $\mathrm{O}$ cacau por ser rico em flavonoides (pertence a uma classe dos polifenóis), tem capacidade antioxidante, sua ingestão pode reduzir a mortalidade por doença cardiovascular, pois melhora: a sensibilidade à insulina; controla a pressão arterial e reduz agregação plaquetária (D'EL REI; MEDEIROS, 2011).

O presente trabalho teve como objetivo, desenvolver e avaliar as características físico-químicas e sensoriais de uma massa de brigadeiro com teor reduzido de lactose. Dessa forma, foram elaboradas três diferentes formulações de brigadeiro com reduzido teor de lactose, utilizando leite de arroz e leite condensado sem lactose como base.

\section{MATERIAL E MÉTODOS}

\subsection{Elaboração do brigadeiro}

Foram elaboradas três formulações de massa de brigadeiro com teor reduzido de lactose (traços de lactose), onde se utilizou leite de arroz (feito a partir de arroz branco tipo 1), margarina sem sal, açúcar, leite condensado sem lactose e chocolate $70 \%$ cacau, como matérias-primas. Os produtos utilizados no preparo das formulações foram adquiridos no comércio local e a única especificação técnica é a ausência ou teor reduzido (traços) de lactose na formulação. As três diferentes formulações foram nomeadas A, B e C, onde se variou as quantidades utilizadas de leite de arroz e leite condensado sem lactose, conforme expresso na Tabela 1.

Tabela 1- Proporções de Ingredientes utilizadas nas formulações testadas

\begin{tabular}{c|c|c|c|c|c}
\hline Formulação & \multicolumn{5}{|c}{ Quantidade de cada ingrediente para produzir aproximadamente } \\
& $\begin{array}{c}\text { Chocolate } \\
(\mathrm{g})\end{array}$ & $\begin{array}{c}\text { Açúcar } \\
(\mathrm{g})\end{array}$ & $\begin{array}{c}\text { Margarina } \\
(\mathrm{g})\end{array}$ & $\begin{array}{c}\text { Leite de arroz } \\
(\mathrm{g})\end{array}$ & $\begin{array}{c}\text { Leite condensado } \\
\text { sem lactose }(\mathrm{g})\end{array}$ \\
\hline A & 210 & 250 & 5 & 450 & 450 \\
\hline B & 210 & 250 & 5 & 300 & 600 \\
\hline C & 210 & 250 & 5 & 600 & 300 \\
\hline
\end{tabular}

Fonte: Dos autores (2015). 
As formulações foram produzidas e testadas no laboratório de tecnologia de alimentos, do Centro Universitário UNIVATES e o experimento foi conduzido por alunos dos cursos de Engenharia de Alimentos e Química Industrial.

O arroz foi devidamente cozido, triturado e filtrado (coado). Foram utilizadas 225 gramas de arroz branco tipo 1, da marca Prato Belo (o equivalente a uma xícara grande) que foi cozido (sem adição de sal e óleo) com $600 \mathrm{~mL}$ de água. Após a hidratação foi liquidificado, com a adição de mais 1 litro de água, e coado para separação de partículas que não tenham sido trituradas, para garantia de obtenção de uma massa lisa.

Em recipientes de inox, foram adicionadas conforme descrito na Tabela 1, diferentes porções de leite de arroz e leite condensado sem lactose da marca Piracanjuba. Os demais ingredientes nas quantidades de: $250 \mathrm{~g}$ de açúcar refinado da marca Caiano; $5 \mathrm{~g}$ de margarina sem sal da marca Doriana e $210 \mathrm{~g}$ (1 barra e meia) de chocolate em barra $70 \%$ cacau da marca Arcor.

Misturaram-se todos os ingredientes, procedeu-se com o cozimento em banho-maria, com agitação constante, até que a massa se desprendesse do fundo do recipiente. Resfriou-se em uma bandeja com banho de gelo, separaram-se porções para realização da análise sensorial e análises físico-químicas.

\subsection{Análise sensorial}

Para avaliação sensorial serão consideradas normas vigentes. A NBR 12994/1993 define os métodos de análise sensorial para alimentos e bebidas. Dois tipos de testes existem, os discriminativos e os descritivos. No caso do presente trabalho, será aplicado o teste descritivo, que tem o objetivo de caracterizar qualitativamente e quantitativamente as amostras, utilizando escalas de intervalo ou de proporção para a avaliação de cinco atributos (aparência, aroma, sabor, textura e aceitação global). É considerado um dos métodos mais completos e sofisticados para a caracterização sensorial (LONGO, 2006).

O processamento dos dados foi realizado através do Microsoft Office Excel versão 2010 e a apresentação dos resultados realizada através de gráficos e tabelas.

A análise sensorial do brigadeiro foi realizada com 85 indivíduos adultos não treinados, faixa etária entre 20 e 45 anos, no Laboratório de Análise Sensorial do Centro Universitário UNIVATES, em cabines individuais, sob iluminação de lâmpadas fluorescentes não individuais.

As amostras foram dispostas em prato plástico branco, com 1 colherada de cada brigadeiro (aproximadamente 3 gramas), foram codificadas com números aleatórios de três dígitos. Apresentadas aos provadores, juntamente com um copo de água mineral a temperatura ambiente para limpeza do palato, 
e a ficha do teste contendo uma escala hedônica, teste de aceitação, e intenção de compra.

Foi aplicado um questionário de aceitabilidade por análise sensorial com escala hedônica estruturada de nove pontos correspondentes, respectivamente a 1, desgostei muitíssimo; 2 desgostei muito, 3 desgostei moderadamente; 4, desgostei ligeiramente; 5 , não gostei nem desgostei; 6 , gostei ligeiramente; 7 , gostei moderadamente; 8 , gostei muito e 9 , gostei muitíssimo.

Também foi avaliado o teste de intenção de compra com escala hedônica de cinco pontos correspondentes, respectivamente a 1 , certamente não compraria; 2 provavelmente não compraria, 3 tenho dúvidas se compraria; 4 , provavelmente compraria e 5 , certamente compraria.

\subsection{Análise estatística}

Os dados referentes ao teste sensorial de aceitação foram submetidos à análise estatística, por meio de ANOVA (análise de variância), utilizou-se nível de significância de $95 \%$. A aceitação dos produtos, para cada atributo, foi calculada por meio do índice de aceitabilidade (IA), conforme Equação 1, descrita por Dutcoski (2011).

$$
\mathrm{IA}(\%)=(\mathrm{A} / \mathrm{B}) \times 100
$$

Onde, A é a média dos resultados do teste de aceitação, para cada produto e B é a maior nota obtida no teste de aceitação, para cada atributo.

Previamente ao teste sensorial, aplicou-se um questionário estruturado para avaliar a intenção de compra dos provadores.

\subsection{Análises Físico-químicas}

As determinações dos teores: de umidade em estufa (método gravimétrico), do resíduo mineral fixo (cinzas) por incineração em mufla (Marconi MA 385/2, Piracicaba, SP) a $550{ }^{\circ} \mathrm{C}$, de proteínas por meio da determinação do teor de nitrogênio total pelo método de Macro-Kjeldahl, e de lipídeos pelo método Roese-Gottlieb (Mojonnier).

As análises físico-químicas foram realizadas nos laboratórios de química do prédio 8, do Centro Universitário UNIVATES.

O teor de carboidratos totais foi determinado pelo cálculo da diferença de 100 gramas de amostra e a soma total dos valores encontrados de proteínas, lipídios, cinzas e umidade. $\mathrm{O}$ valor calórico foi calculado pela soma dos resultados da multiplicação das porcentagens de proteínas, carboidratos e lipídeos pelos seus respectivos fatores de conversão (4; 4 e 9 kcal/g). Todas as análises foram realizadas em triplicata. 


\subsubsection{Materiais para análise de umidade}

Estufa, balança analítica, dessecador com sílica gel, cápsula de porcelana ou de metal de $8,5 \mathrm{~cm}$ de diâmetro, pinça e espátula de metal.

\subsubsection{Procedimento para análise de umidade}

Pesou-se de 2 a $10 \mathrm{~g}$ da amostra em cápsula de porcelana ou de metal, previamente tarada. Aqueceu-se a amostra em estufa durante 2 horas. Resfriou-se em dessecador até a temperatura ambiente. Pesou-se em uma balança analítica. Repetiu-se a operação de aquecimento e resfriamento até peso constante.

\subsubsection{Cálculo para determinação de resultados de umidade}

Equação 2, cálculo para determinação de percentual de umidade.

$\%$ umidade $=\frac{((\mathrm{m} 1+\mathrm{m} 0)-\mathrm{m} 2) \times 100}{\mathrm{~m} 0}$

Sendo:

$\mathrm{m}_{0}=$ massa da amostra, em gramas.

$\mathrm{m}_{1}=$ massa da cápsula sem amostra, em gramas.

$\mathrm{m}_{2}=$ massa da cápsula com amostra seca, em gramas.

\subsubsection{Materiais para análise de cinzas}

Cadinho de porcelana de $50 \mathrm{~mL}$, mufla, balança analítica, banho-maria, dessecador com sílica, chapa elétrica, balança analítica, espátula e pinça de metal.

\subsubsection{Procedimento para análise de cinzas}

Pesou-se de 5 a $10 \mathrm{~g}$ da amostra em um cadinho, previamente aquecida (calcinado) em mufla a $550^{\circ} \mathrm{C}$, resfriada em dessecador até a temperatura ambiente e pesada.

A amostra líquida foi evaporada em banho-maria e seca em chapa elétrica e após incinerada em mufla a $550^{\circ} \mathrm{C}$, por 3 horas, até que se obteve cinzas totalmente brancas. Após resfriou-se em dessecador até a temperatura ambiente e pesou-se em balança analítica.

\subsubsection{Cálculo para determinação de resultados de cinzas}

Equação 3, cálculo para a determinação de umidade. 
$\%$ cinzas $=\frac{(\mathrm{m} 2-\mathrm{m} 1) \times 100}{\mathrm{~m} 0}$

Onde:

$\mathrm{m}_{0}=$ massa da amostra, em gramas .

$\mathrm{m}_{1}=$ massa cadinho de porcelana sem amostra, em gramas.

$\mathrm{m}_{2}=$ massa cadinho de porcelana com amostra após incineração, em gramas.

\subsubsection{Materiais para análise de proteína}

Balança analítica, bloco digestor, destilador, capela de exaustão, tubos de digestão, bureta $25 \mathrm{~mL}$, papel manteiga, erlenmeyer $250 \mathrm{~mL}$ e $500 \mathrm{~mL}$, proveta $100 \mathrm{~mL}$, pipeta volumétrica $10 \mathrm{~mL}$, papel alumínio e tenaz.

\subsubsection{Reagentes para análise de proteína}

Ácido sulfúrico PA, mistura catalítica, indicador misto, ácido bórico 4\%, $\mathrm{NaOH} 50 \%$ e ácido sulfúrico $0,1 \mathrm{~N}$.

\subsubsection{Procedimento para análise de proteína}

Pesou-se $0,5 \mathrm{~g}$ de amostra homogeneizada em papel manteiga. Transferiuse para tubo de digestão. Adicionou-se $5 \mathrm{~g}$ de mistura catalítica. Adicionou-se 10 $\mathrm{mL}$ de Ácido sulfúrico PA. Acoplou-se os tubos no bloco aquecedor, colocandonos um pedaço de papel alumínio com um furo no centro para a saída do gás, e ligou-se a capela. Digeriu-se as amostras por 30 minutos a $420^{\circ} \mathrm{C}$. Deixou-se os tubos esfriarem fora do bloco digestor, com sistema de exaustão ligado por alguns minutos até não haver mais a formação de fumos no interior dos tubos.

Após isto para a destilação, ligou-se o destilador. Encheu-se a caldeira com água até o nível indicado e deixou-se a mesma aquecer. Colocou-se o tubo na unidade de destilação e adicionou-se no local indicado $60 \mathrm{~mL}$ de $\mathrm{NaOH} 50 \%$ e $50 \mathrm{~mL}$ de água deionizada. Recolheu-se o destilado em erlenmeyer contendo $20 \mathrm{~mL}$ de Ácido bórico 4\%, $80 \mathrm{~mL}$ de água deionizada e 8 gotas do Indicador misto. Destilou-se até que toda a amônia fosse liberada (recolhendo $150 \mathrm{~mL}$ ). Titulou-se com Ácido sulfúrico 0,1N (padronizado).

\subsubsection{Cálculos para determinação de resultados de proteína}

Equação 4, cálculo para determinação de percentual de proteína bruta.

$\%$ Proteína bruta $=\frac{(\mathrm{Va}-\mathrm{Vb}) \times 0,014 \times \mathrm{N} \times 6,38 \times 100 \times \mathrm{F}}{\mathrm{P}}$

Sendo:

$\mathrm{Va}=\mathrm{mL}$ gastos na titulação. 
$\mathrm{Vb}=\mathrm{mL}$ gastos com o branco.

0,014 = miliequivalente grama do nitrogênio.

$\mathrm{N}=$ normalidade do Ácido sulfúrico 0,1N.

$\mathrm{F}=$ fator de correção do Ácido sulfúrico 0,1N.

$\mathrm{P}=$ peso da amostra $(\mathrm{g})$.

Fator de transformação do nitrogênio em proteína:

6,38 = Produtos lácteos.

\subsection{Método analítico para análise de gordura, conforme Mapa (2006).}

\subsubsection{Materiais para análise de gordura}

Béqueres de 150 a $250 \mathrm{~mL}$, frascos de extração do tipo Mojonnier, pipeta graduada de $10 \mathrm{~mL}$, proveta de $25 \mathrm{~mL}$, bastão de vidro, termômetro calibrado, tenaz metálica, dessecador, suporte para frascos de Mojonnier, balança analítica, estufa a temperatura de $102+2^{\circ} \mathrm{C}$ e chapa de aquecimento ou banho-maria.

\subsubsection{Reagentes para análise de gordura}

Álcool etílico PA, solução de amônia contendo aproximadamente 25 \% $(\mathrm{m} / \mathrm{m})$ de $\mathrm{NH}_{3}$, densidade $910 \mathrm{~g} / \mathrm{L}$, ou superior de concentração conhecida, solução de vermelho Congo a $1 \%,(\mathrm{~m} / \mathrm{v})$, se necessário, éter etílico PA, livre de peróxidos e oxidantes e éter de petróleo PA.

\subsubsection{Procedimento para análise de gordura}

Retirou-se a umidade do béquer de 150 ou $250 \mathrm{~mL}$ por 1 hora em estufa a $102 \pm 2^{\circ} \mathrm{C}$. Esfriou-se em dessecador. Pesou-se e reservou-se para recepção da gordura.

Pesou-se exatamente de 2 a $5 \mathrm{~g}$ da amostra homogeneizada em béquer, acrescentou-se cerca de $10 \mathrm{~mL}$ de água dividida em três pequenas porções. Para cada porção de água adicionada realizou-se a transferência quantitativa para o frasco de Mojonnier, com auxílio de um bastão de vidro.

Após o preparo das amostras, adicionou-se $2 \mathrm{~mL}$ da solução de amônia (ou volume equivalente de uma solução mais concentrada) ao frasco de Mojonnier e misturou-se. A partir desse ponto, a análise foi conduzida imediatamente.

Acrescentou-se $10 \mathrm{~mL}$ de álcool etílico e misturou-se cuidadosamente, sem agitação forte, mas deixando o líquido fluir entre os dois bulbos, inclinando o frasco de extração sem que o líquido atingisse a "boca". Adicionou-se $25 \mathrm{~mL}$ de éter etílico e agitou-se o frasco de extração por 1 minuto com o frasco na posição horizontal e o bulbo menor voltado para cima. Adicionou-se $25 \mathrm{~mL}$ de 
éter de petróleo e agitou-se por 30 segundos. Deixou-se o frasco de Mojonnier em repouso por 30 minutos no seu suporte. Transferiu-se o sobrenadante para o béquer (preparado anteriormente), segurando o frasco de extração pelo bulbo menor. Adicionou-se $5 \mathrm{~mL}$ de álcool etílico ao frasco de Mojonnier. Conduziuse uma segunda extração, usando $15 \mathrm{~mL}$ dos éteres etílico e de petróleo. Realizou-se uma terceira extração, omitindo o uso do álcool. Transferiu-se o sobrenadante para o béquer.

Removeu-se os solventes, incluindo o álcool, por evaporação. Transferiuse o béquer para estufa a $102+2^{\circ} \mathrm{C}$ por 1 hora com auxílio da tenaz metálica. Removeu-se o frasco da estufa, deixou-se esfriar por aproximadamente 10 minutos e pesou-se. Repetir o procedimento até massa constante.

\subsubsection{Cálculo para determinação de resultados de gordura}

Equação 5, cálculo para determinação percentual de gordura.

$\%$ de gordura $=\frac{(\mathrm{m} 1-\mathrm{m} 2) \times 100}{\mathrm{~m} 0}$

Onde:

$\mathrm{m} 0=$ massa da amostra, em gramas

$\mathrm{m} 1$ = massa do béquer com gordura (massa constante), em gramas

$\mathrm{m} 2$ = massa inicial do béquer, em gramas .

\section{RESULTADOS E DISCUSSÃO}

\subsection{Avaliação Sensorial}

Na Tabela 2 constam as médias e seus respectivos desvios padrões, bem como a análise estatística para as amostras estudadas: A (1:1), B (1:2) e C (2:1).

Tabela 2- Média e desvios padrões para cada atributo avaliado em Análise sensorial para as amostras A (1:1), B (1:2) e C (2:1)

\begin{tabular}{l|l|l|l|l|l|l}
\hline Atributo & Amostra A & DP & Amostra B & DP & Amostra C & DP \\
\hline Aparência & $7,83^{\mathrm{A}}$ & 0,98 & $7,75^{\mathrm{A}}$ & 1,21 & $7,95^{\mathrm{A}}$ & 0,96 \\
\hline Odor & $7,68^{\mathrm{A}}$ & 1,12 & $7,70^{\mathrm{A}}$ & 1,22 & $7,78^{\mathrm{A}}$ & 1,07 \\
\hline Textura & $6,70^{\mathrm{A}}$ & 1,6 & $6,78^{\mathrm{A}}$ & 1,64 & $7,48^{\mathrm{A}}$ & 1,2 \\
\hline $\begin{array}{l}\text { I m p r e s s ã o } \\
\text { global }\end{array}$ & $7,48^{\mathrm{A}}$ & 0,99 & $7,43^{\mathrm{A}}$ & 1,28 & $7,48^{\mathrm{A}}$ & 1,15 \\
\hline Sabor & $7,33^{\mathrm{A}}$ & 1,02 & $7,20^{\mathrm{A}}$ & 1,62 & $7,60^{\mathrm{A}}$ & 1,45 \\
\hline
\end{tabular}

${ }^{\text {A }}$ As amostras não diferem significativa pelo teste ANOVA, a 95\% de confiança. Fonte: Dos autores (2015). 
Pela análise estatística pôde-se observar que não houve variações significativas entre as amostras em nenhum dos cinco atributos, atingindo nosso objetivo inicial de desenvolver um produto inovador, adicionado de ingredientes possíveis de caracterizar um alimento funcional e mantendo a aceitação sensorial do produto tradicional.

Na Figura 1, são apresentados os valores para o Índice de aceitação para cada atributo. Segundo Dutcosky (2011), para que o produto apresente uma aceitabilidade satisfatória, o índice deve ser maior ou igual a 70\%.

Figura 1 - Índice de aceitação para cada atributo avaliado em Análise sensorial para as amostras A (1:1), B (1:2) e C (2:1)

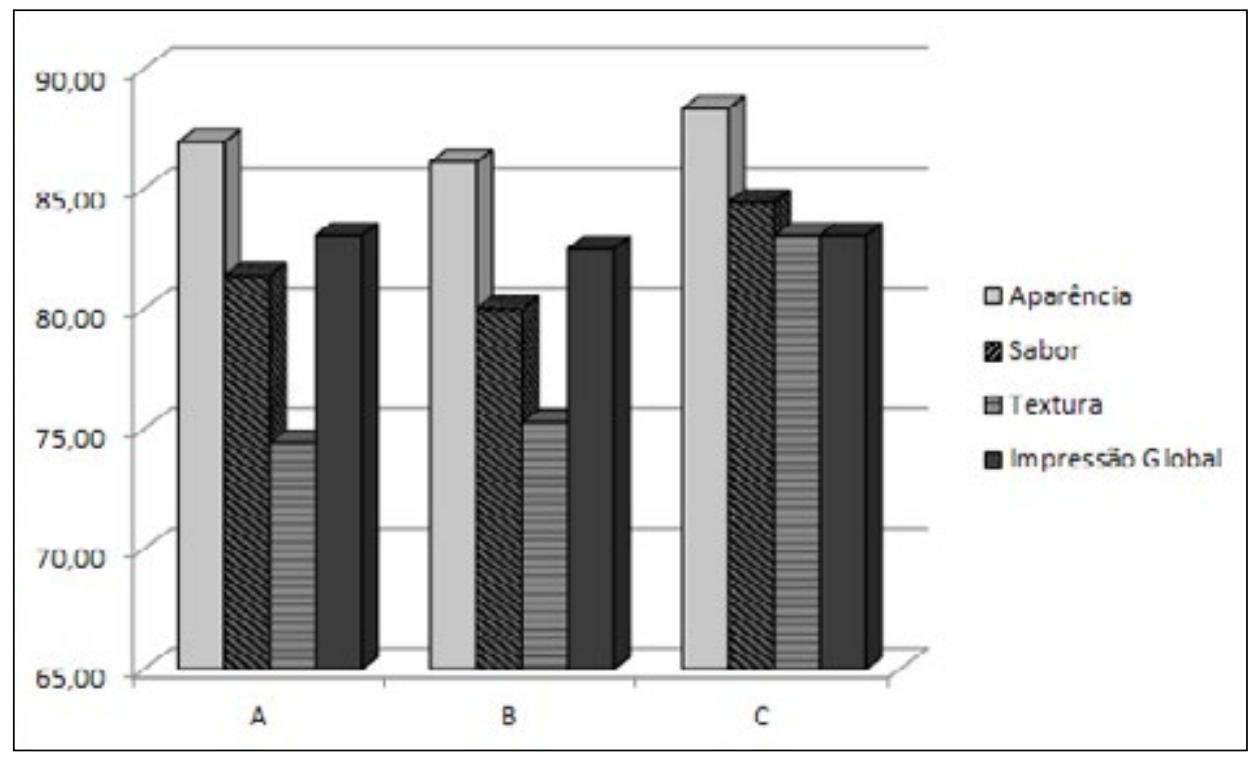

Fonte: Dos autores (2015).

Assim, verifica-se que os produtos obtiveram valores maiores que $70 \%$ para o Índice de Aceitação de cada atributo sensorial, principalmente em relação à aparência, fator limitante para a comercialização do produto (DUTCOSKI, 2011). Os julgadores comentaram que a textura das formulações A e $B$, que possuíam maior quantidade de leite condensado sem lactose, estavam mais consistentes e também apresentavam cristalização, quando comparado com a formulação C. Atribui-se a esse resultado o fato das amostras terem sido conservadas com refrigeração (cristalização dos açúcares por ter sido concentrado), sendo que a amostra de julgadores não ser composta unicamente por pessoas que tinham o hábito de ingerirem produtos refrigerados, e sim de produtos preparados e consumidos imediatamente.

$\mathrm{Na}$ Figura 2, têm-se resultados da intenção de compra de cada formulação avaliada na análise sensorial. 
Figura 2 - Intenção de compra de cada formulação avaliada na análise sensorial para as amostras A (1:1), B (1:2) e C (2:1)

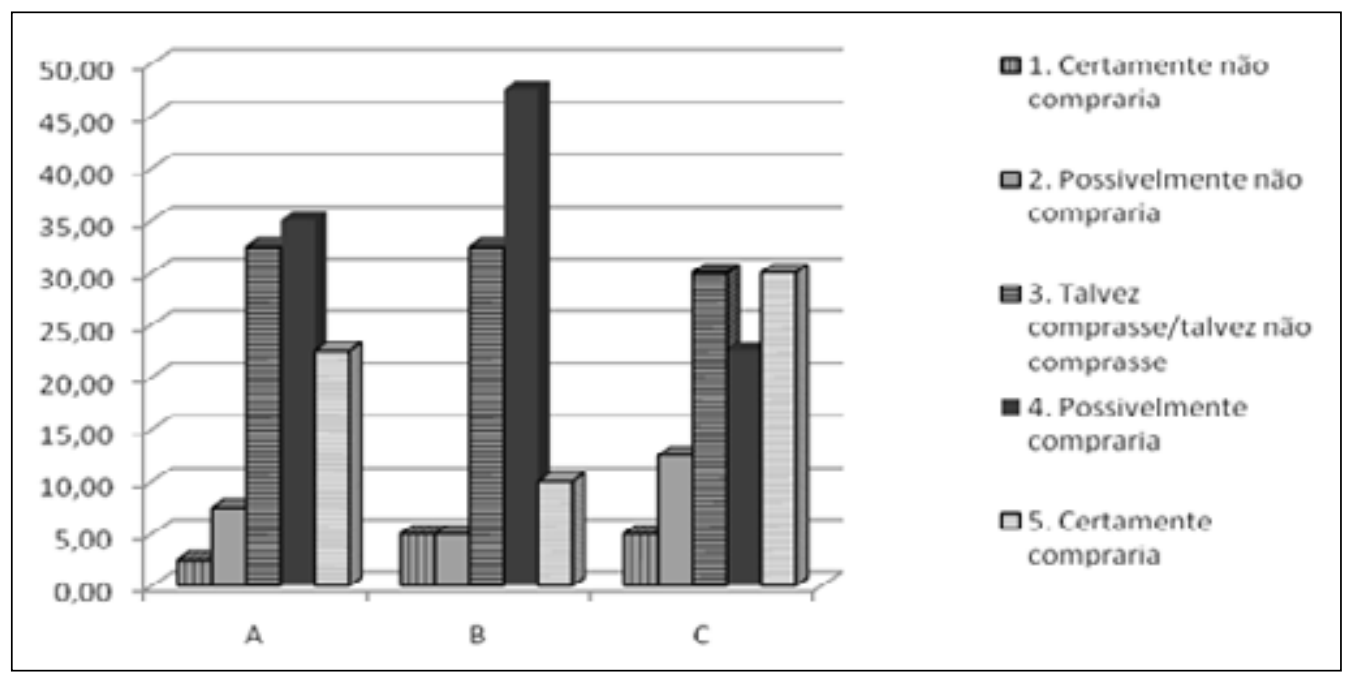

Fonte: Dos autores (2015).

Não foram encontrados na literatura trabalhos em que tenham sido utilizados leite de arroz e leite condensado sem lactose juntos como matériasprimas principais. Portanto, os resultados obtidos foram comparados com os do produto elaborado por Silva et al. (2014) que utilizou biomassa de banana verde e farinha de arroz.

Silva et al. (2014) avaliaram a aceitação de um doce "brigadeiro" sabor chocolate com potencial funcional elaborado com a biomassa da banana verde e farinha de arroz. Foram avaliados os atributos aparência, cor, sabor, textura e aroma e a intensão de compra do produto elaborado. O brigadeiro apresentou boa aceitação e índice de aceitação superior a 70\%, observando uma oportunidade de elaboração para melhorar os hábitos alimentares da população.

Para comparação entre os trabalhos quanto aos atributos sensoriais, calculou-se o valor médio das três formulações produzidas no presente trabalho e comparou-se com as do trabalho citado acima, exceto no atributo Impressão Global que não foi avaliado por Silva et al. (2014). As médias obtidas em ambos os trabalhos constam na Tabela 3. 
Tabela 3 - Comparação dos atributos sensórios entre o trabalho apresentado no presente artigo e o elaborado por Silva et al. (2014)

\begin{tabular}{c|c|c}
\hline Atributo & Silva et al. (2014) & Presente artigo \\
\hline Aparência & 7,98 & 7,84 \\
\hline Odor & 7,82 & 7,72 \\
\hline Textura & 7,33 & 6,99 \\
\hline Sabor & 6,85 & 7,38 \\
\hline
\end{tabular}

Fonte: Dos autores (2015).

Avaliando os dados da Tabela 3, percebe-se que os resultados obtidos na análise sensorial dos produtos produzidos assemelham-se bastante principalmente no atributo odor. No atributo sabor, as formulações obtidas no presente trabalho, mostraram-se com aceitação um pouco mais favorável que a obtida por Silva et al. (2014). Quanto aos quesitos aparência e textura, os resultados obtidos foram bastante similares.

\subsection{Análises físico-químicas}

Na Tabela 4 constam os resultados das análises físico-químicas realizadas em cada uma das formulações, os resultados descritos foram calculados a partir das médias dos resultados obtidos, na triplicata de cada ensaio realizado e também o desvio padrão entre as três amostras.

Tabela 4 - Resultados das análises físico-químicas de cada formulação avaliada para as amostras A (1:1), B (1:2) e C (2:1)

\begin{tabular}{|c|c|c|c|c|}
\hline \multirow{2}{*}{ Análise } & \multicolumn{3}{|c|}{ Amostras } & \multirow{2}{*}{$\begin{array}{c}\text { Desvio padrão } \\
\text { entre amostras } \\
\text { A, B e C. }\end{array}$} \\
\hline & A & B & $\mathrm{C}$ & \\
\hline Umidade (\% m/m) & $23,67 \pm 0,20$ & $22,2 \pm 0,15$ & $33,92 \pm 0,18$ & 6,38 \\
\hline Gordura $(\% \mathrm{~m} / \mathrm{m})$ & $8,23 \pm 0,07$ & $11,63 \pm 0,07$ & $10,18 \pm 0,07$ & 1,71 \\
\hline Cinzas $(\% \mathrm{~m} / \mathrm{m})$ & $2,53 \pm 0,02$ & $2,76 \pm 0,03$ & $2,38 \pm 0,05$ & 0,19 \\
\hline Proteína bruta $(\%$ m/m) & $18,21 \pm 0,15$ & $15,27 \pm 0,12$ & $14,48 \pm 0,18$ & 1,97 \\
\hline Carboidratos (\% m/m) & $47,36 \pm 0,44$ & $48,14 \pm 0,37$ & $39,04 \pm 0,48$ & 5,04 \\
\hline Valor calórico (kcal/20 g) & 67,27 & 71,66 & 61,14 & 6,04 \\
\hline
\end{tabular}

Fonte: Dos autores (2015). 
Não existe legislação vigente específica para este produto desenvolvido, mas a resolução - CNNPA n ${ }^{\circ}$ 12, de 1978 da ANVISA, dispõe alguns critérios para a padronização de doce de leite que serão tomados como base, como umidade máxima de $30 \%$, lipídios com o mínimo de 2,0\% e proteínas com o mínimo de 6,0\% e cinzas de no máximo 2,0\% (CNNPA, 1978).

Assim, percebe-se que a umidade do brigadeiro desenvolvido na amostra C, superou o limite da resolução para doce de leite em pasta, as amostras A e B estão com umidade abaixo de $30 \%$, resultado conforme o estabelecido em CNNPA (1978). Para corrigir o percentual de umidade da amostra C, sugere-se aumentar o tempo de cozimento, corrigindo-se assim o percentual de umidade, pois nesta formulação foi utilizada uma maior quantidade de leite de arroz, deixando-se esta formulação com valores conforme resolução vigente.

Os teores de lipídios e proteínas, das três formulações estão de acordo com resolução, CNNPA (1978). O valor nutricional dos produtos desenvolvidos é muito importante, pois este é bastante popular e consumido em sua grande maioria por crianças.

As formulações apresentaram teor de cinzas, maior que o valor de $2,0 \%$ descrito em CNNPA (1978), estando inadequado. Isso se deve provavelmente ao fato de ter sido usado chocolate amargo, com $70 \%$ de cacau, pois conforme descrito em TACO (2010); 100g de parte comestível de chocolate meio amargo possuem $1,8 \mathrm{~g}$ de cinzas e os demais ingredientes utilizados: leite condensado 1,6g; arroz tipo 1 cozido 0,5g e o açúcar possui traços de cinzas (valores menores que $0,05 \%$ ). Mas, conforme já descrito, não existe uma legislação vigente específica para o produto desenvolvido e também o resultado qualifica o produto, já que a um incremento da característica nutritiva do mesmo, com o aumento do teor de cinzas contido neste.

Com estes resultados obtidos, comprovou-se que o leite de arroz pode substituir parcialmente o leite condensado deixando o produto com características sensoriais de brigadeiro, mas com menos gordura e mais proteína se comparado ao brigadeiro tradicional, que segundo a TACO (2010) apresenta em $100 \mathrm{~g}$ de alimento $4,90 \mathrm{~g}$ de proteína e $27,28 \mathrm{~g}$ de lipídios totais, ou seja, o produto desenvolvido pode ser qualificado positivamente, já que o mesmo supera os valores de proteína contidos no brigadeiro tradicional em todas as amostras das 3 formulações desenvolvidas, sendo em 3,72 vezes na amostra A, 3,12 vezes na amostra B e 2,96 vezes na amostra $C$. Também em relação à gordura, da mesma forma em ambas as formulações desenvolvidas, esta foi reduzida, onde na formulação $A$, se obteve uma redução de 3,31 vezes, na formulação $B, 2,35$ vezes e na formulação $C, 2,68$ vezes. Assim, todas as formulação desenvolvidas, obtiveram resultados superiores em termos de proteína e inferiores em relação à gordura, quando comparadas ao brigadeiro tradicional, sendo o melhor resultado da formulação A, em ambos os resultados. Estes resultados tornam as formulações desenvolvidas bastante nutritivas e 
pouco calóricas, qualificando positivamente o produto desenvolvido em ambas as formulações.

\section{CONCLUSÃO}

Todos os objetivos do trabalho foram alcançados com êxito, pois as três formulações de brigadeiro com teor reduzido de lactose, foram elaboradas e em análise sensorial realizada, obtiveram mais de 70\% de índice de aceitação em todos os atributos avaliados, obtiveram-se valores bastantes semelhantes à referência em que o trabalho foi comparado e superior no atributo sabor. Nos resultados físico químicos, valores bastante positivos foram obtidos, que qualificam o produto desenvolvido, em ambas as formulações desenvolvidas, comparadas com o produto brigadeiro tradicional, já que se obteve um alto teor de cinzas, com média de $2,56 \%$, um alto teor de proteína, com média de 3,27 vezes superior e um baixo teor de gordura, com média 2,78 vezes inferior aos resultados físico químicos de um brigadeiro tradicional. Assim, o valor nutricional dos produtos desenvolvidos é muito importante, e foi bastante positivo, pois este é bastante popular e consumido em sua grande maioria por crianças. Além disto, mostrou-se uma alternativa viável de consumo para as pessoas intolerantes à lactose, desenvolvendo-se um produto inovador, adicionado de ingredientes possíveis de caracterizar um alimento funcional e mantendo a aceitação sensorial do produto tradicional. O produto é potencialmente comercializável para este nicho de mercado. Devem-se considerar os nutrientes disponíveis no leite de arroz que, consequentemente, estarão contidos em sua grande maioria no brigadeiro, independentemente da formulação, podendo ser uma alternativa viável, auxiliando na alimentação infantil, já que o consumo deste produto é ainda mais popular nesta faixa etária.

\section{REFERÊNCIAS}

ABNT - Associação Brasileira de Normas Técnicas. NBR 12994: Métodos de análise sensorial dos alimentos e bebidas. Rio de Janeiro: ABNT, 1993.

ARAÚJO, W. et al. Alquimia dos Alimentos. Brasília: Senac, 2012.

COMISSÃO NACIONAL DE NORMAS E PADRÕES PARA ALIMENTOS - CNNPA. Resolução no 12, de 1978, ANVISA. Disponível em: <http:/ / www.anvisa.gov.br/ anvisalegis/resol/12_78_prod_confeita.htm>. Acesso em: 20 mai. 2016.

CUNHA, M. E. T. et al. Intolerância à lactose e alternativas tecnológicas. Científica Ciências Biológicas e da Saúde, Londrina, v. 10, n. 2, p. 83-88, out. 2008. Disponível em: <pgsskroton.com.br/seer/index.php/JHealthSci/article/download/1523/1460>. Acesso em: 25 mar. 2016.

D'EL REI, J.; MEDEIROS, F. Chocolate e os benefícios cardiovasculares. Revista do Hospital Universitário Pedro Ernesto, Rio de Janeiro, v. 3, n. 3, jul./set. 2011. 
Disponível em: <http:/ / revista.hupe.uerj.br/detalhe_artigo.asp?id=94>. Acesso em: 20 maio 2016.

DUTCOSKY, S. D. (2011). Análise sensorial de alimentos. (3 ed). Curitiba: Champagnat.

FAEDO, R. et al. Obtenção de leite com baixo teor de lactose por processos de separação por membranas associados à hidrólise enzimática. Revista CIATEC, Passo Fundo, v. 3, n. 1, p. 44-54, 2013. Disponível em: <http:/ / seer.upf.br/index.php/ ciatec/article/view/3222/2386>. Acesso em: 21 abr. 2016.

FEDERAÇÃO DAS INDÚSTRIAS DO ESTADO DE SÃO PAULO- FIESP. Brasil Food Trends 2020. São Paulo, 2010. Disponível em:<http:/ / www.brasilfoodtrends.com.br/ Brasil_Food_Trends/index.html>. Acesso em: 2 mar. 2016.

GASPARIN, F. S. R.; TELES, J. M.; ARAÚJO, S. C. Alergia à proteína do leite de vaca versus intolerância à lactose: as diferenças e semelhanças. Revista Saúde e Pesquisa, v. 3, n. 1, p. 107-114, jan./abr. 2010. Disponível em: <http:/ / periodicos.unicesumar. edu.br/index.php/saudpesq/article/view/1069/1045>. Acesso em: 26 mar. 2016.

HEISLER, G. E. R et al. Viabilidade da substituição da farinha de trigo pela farinha de arroz na merenda escolar. Alimentos e Nutrição, Araraquara, v. 19, n. 3, p. 299306, jul./set. 2008. Disponível em: <http:/ / serv-bib.fcfar.unesp.br/seer/index.php/ alimentos/article/viewFile/634/532>. Acesso em: 22 maio 2016.

INGREDIENTES: novas funcionalidades. Food Ingredients Brasil, São Paulo, n. 14, pg. 35- 41, jun./jul. 2010. Disponível em: <http://www.revista-fi.com/materias/144. pdf >. Acesso em: 26 mar. 2016.

INSTITUTO ADOLFO LUTZ. Métodos físico-químicos para análise de alimentos. 4. ed. 1. ed. digital. São Paulo, 2008. E-book. Disponível em: <http:/ /www.crq4.org.br/ sms/files/file/analisedealimentosial_2008.pdf>. Acesso em: 3 out. 2016.

JUNIOR, M. S. S. et al. Bebidas saborizadas obtidas de extratos de quirera de arroz, de arroz integral e de soja. Ciência e Agrotecnologia, Lavras, v. 34, n. 2, p. 407-413, mar./abr. , 2010. Disponível em: <http:/ / www.scielo.br/scielo.php?script=sci_ arttext\&pid=S1413-70542010000200019 > . Acesso em: 22 mai. 2016.

LONGO, G. A influência da adição de lactase na produção de iogurtes. 2006. 109 f. Dissertação (Mestrado em Tecnologia de Alimentos) - Programa de PósGraduação em Tecnologia de Alimentos, Setor de Tecnologia, Universidade Federal do Paraná, Curitiba, 2006. Disponível em: <http:/ /acervodigital.ufpr.br/bitstream/ handle/1884/4949/Disserta\%C3\%A7\%C3\%A30\%20GIOVANA \%20LONGO $\% 20-\% 20$ Tec\%20Alimentos\%20-\%202006.pdf?sequence=1\&isAllowed=y>. Acesso em: 22 maio 2016.

MATTAR, R.; MAZO, D. F. de C. Intolerância à lactose: mudança de paradigmas com a biologia molecular. Revista da Associação Médica Brasileira, São Paulo, 
Brasil, v. 56, n. 2, p. 230-236, 2010. Disponível em: <http:/ /www.scielo.br/scielo. php?script=sci_arttext\&pid=S0104-42302010000200025>. Acesso em: 23 mar. 2016.

MINISTÉRIO DA AGRICULTURA, PECUÁRIA E ABASTECIMENTO-MAPA. Instrução Normativa $N^{\circ}$ 68, DE 12 de dezembro de 2006. Disponível em: <http:/ / extranet.agricultura.gov.br/sislegis-consulta/consultarLegislacao. do?operacao=visualizar\&id=17472> . Acesso em: 23 mar. 2016.

PEREIRA, M. C. S. et al. Lácteos com baixo teor de lactose: uma necessidade para portadores de má digestão da lactose e um nicho de mercado. Revista do Instituto de Laticínios Cândido Tostes, Minas Gerais, v. 67, n. 389, p. 57-65, 2012. Disponível em: <https:/ / www.revistadoilct.com.br/rilct/article/view/227/237>. Acesso em: 23 mar. 2016.

SALGADO, J. M. et al. Impacto de alimentos funcionais para saúde. Nutrição em Pauta, v. 48., p. 10-17, maio/ jun. 2001. Disponível em: <http:/ / www. nutricaoempauta.com.br/lista_artigo.php?cod=446>. Acesso em: 22 maio 2016.

SANTIN, J. Intolerância à lactose: novos entendimentos. Milk Point, Piracicaba, 2010. Disponível em: <http:/ / www.milkpoint.com.br/cadeia-do-leite/leite-saude/ intolerancia-a-lactose-novos-entendimentos-65465n.aspx>. Acesso em: 25 mar. 2016.

SHINOHARA, N. K. S. et al. Leite condensado: gerações do leite moça. Contextos da Alimentação-Revista de Comportamento, Cultura e Sociedade, v. 2, n. 1, 2013. Disponível em: <http:/ / www.revistas.sp.senac.br/index.php/revistacontextos / article/viewFile/406/346>. Acesso em: 17 mai. 2016.

SILVA, G. M. S. et al. Avaliação sensorial de doce de chocolate "brigadeiro" com potencial funcional. Caderno Verde de Agroecologia e Desenvolvimento Sustentável, Campina Grande, v. 4, n. 1, dez. 2014. Disponível em: <http:/ / www. gvaa.com.br/revista/index.php/CVADS/article/view/2868/2620>. Acesso em: 26 abr. 2016.

TABELA BRASILEIRA DE COMPOSIÇÃO DE ALIMENTOS-TACO. Campinas, São Paulo, 4. ed. 2010. Disponível em: <https://www.unicamp.br/nepa/taco/contar/ taco_4_edicao_ampliada_e_revisada.pdf?arquivo=taco_4_versao_ampliada_e_ revisada.pdf $>$. Acesso em: 17 maio 2016. 